\title{
Influence of Fe addition on annealing behaviors of a phosphorus containing brass
}

Zhenyu Xiao $^{\mathrm{a}}$, Xuyue Yang ${ }^{\mathrm{a}, *}$, Jun Wang ${ }^{\mathrm{b}}$, Zhengwu Fang ${ }^{\mathrm{a}}$, Chengfa Guo ${ }^{\mathrm{a}}$, Duxiu Zhang $^{\text {a }}$, Yi Yang ${ }^{\text {a }}$, Xiangkai Zhang ${ }^{\text {a }}$

${ }^{a}$ Educational Key Laboratory of Nonferrous Metal Materials Science and Engineering, School of Materials Science and Engineering, Central South University, Changsha, 410083, China

${ }^{\mathrm{b}}$ Institute for Frontier Materials, Deakin University, Geelong, 3216, Australia *Corresponding author at: School of Materials Science and Engineering, Central South University, No.932 Lushan South Road, Yuelu District, Changsha 410083, China Tel: +86-731-88876470, fax: +86-731-88830136

E-mail address: yangxycsu@ sina.com

\section{Abstract:}

Effect of Fe addition on annealing behaviors of cold rolled $\mathrm{Cu}-30 \mathrm{Zn}-0.1 \mathrm{P}$ brass was investigated in terms of hardness behavior, microstructure development and microtexture evolution. A maximum increase of about $20 \%$ in hardness was observed with the addition of $\mathrm{Fe}$ before and after annealing. $\mathrm{Fe}_{2} \mathrm{P}$ particles were found dispersed in $\mathrm{Cu}-30 \mathrm{Zn}-0.1 \mathrm{P}-0.5 \mathrm{Fe}$ alloy before and after annealing and they showed great pinning effects and resulted in inhibited recrystallization, grains refinement and thermal stability enhancement. It is also indicated by kernel average misorientation (KAM) maps that a higher dislocation density and energy were stored in the sample with the addition of Fe. As a result, the second phase strengthening and grain boundary strengthening were found to be responsible for the hardness increment for the alloy with the Fe addition. Besides, a higher fraction of Brass texture was found at the beginning of annealing in $\mathrm{Cu}-30 \mathrm{Zn}-0.1 \mathrm{P}-0.5 \mathrm{Fe}$ alloy. The results also showed that Brass texture then translate into 
Brass- $\mathrm{R}$ and $(55 ; 30 ; 0)$ textures during annealing, resulting in high fractions of Brass- $\mathrm{R}$ and $(55 ; 30 ; 0)$ textures in $\mathrm{Cu}-30 \mathrm{Zn}-0.1 \mathrm{P}$ alloy with the addition of Fe after annealing.

Keywords: Cu-Zn-P alloy; recrystallization; second phase particles; EBSD; KAM

\section{Introduction}

$\mathrm{Cu}-\mathrm{Zn}$ brass is known for its good physical and mechanical properties, recyclability and low cost and wildly used in applications such as lead frames, connectors and conducting springs. To keep up with the development in such industries in recent years, $\mathrm{Cu}-\mathrm{Zn}$ brasses with higher mechanical performances and better thermal stability are demanded. Mechanisms for strengthening in alloys usually rely on strategies to improve the density of dislocations or create more internal defects (second phase particles) and boundaries (refined grains) to hinder dislocation motion $[1,2]$. It's popular to enhance the strength by refining grains of the materials through severe plastic deformation (SPD) nowadays [3, 4] but the microstructures and properties usually remain unstable, particularly upon heating $[5,6]$. Therefore, SPD is difficult to be applied widely in industry. By comparison, introducing second phase particles through alloying is a more effective and convenient way to achieve higher strength and thermally stable performance simultaneously of an alloy [7 - 9]. Iron $(\mathrm{Fe})$ is a precipitation strengthening element for copper alloys and previous studies indicate that appropriate amount of $\mathrm{Fe}$ was effective in refining the microstructure and significant enhancement in strength was achieved in copper [10 - 12]. Ye et al. [13] have studied the influence of Fe addition on mechanical performances of $\mathrm{Cu}-\mathrm{Sn}-\mathrm{Zn}$ alloy, where Fe particles were introduced by ageing at $773 \mathrm{~K}$ for $4 \mathrm{~h}$ after solution treatment at $1023 \mathrm{~K}$ for $1 \mathrm{~h}$. The ultimate tensile strength of $\mathrm{Cu}-\mathrm{Sn}-\mathrm{Zn}-\mathrm{Fe}$ was increased by $45 \%$ than those without $\mathrm{Fe}$ addition and its thermal stability is enhanced synchronously. 
Thus, the authors thought Fe could be added in brass to achieve higher mechanical performances as well as better thermal stability. However, it has been reported that each addition of $0.1 \mathrm{wt} \% \mathrm{Fe}$ can cause a decrease of $4 \%$ in elongation in rolled brass [14]. Meanwhile, to avoid undermining the excellent conductivity of the brass, the amount of Fe should be carefully selected [15]. In addition, recovery process from copper scraps is a common link in $\mathrm{Cu}$ alloy industry due to the economic and environmental-friendly demands and impurities such as phosphorus $(\mathrm{P})$ is difficult to expel, which would do harm to the conductivity as well [16]. The addition of Fe, in fact, could also forms a nanoscale intermetallic compound with $\mathrm{P}$ impurities, which would benefit the comprehensive performance of the brass.

In the present work, $\mathrm{Cu}-30 \mathrm{Zn}$ brass alloy containing $\mathrm{P}$ is used. Effects of $\mathrm{Fe}$ on hardness behaviors, microstructural evolution and textures development of the $\mathrm{Cu}-\mathrm{Zn}-\mathrm{P}$ alloy were investigated. The amounts of $0.5 \mathrm{wt} \%$ for $\mathrm{Fe}$ and $0.1 \mathrm{wt} \%$ for $\mathrm{P}$ in the experimental alloy were selected, considering that intermetallic compounds such as $\mathrm{Fe}_{3} \mathrm{P}$ and $\mathrm{Fe}_{2} \mathrm{P}$ would be found.

\section{Materials and Methods}

$\mathrm{Cu}-30 \mathrm{Zn}-0.1 \mathrm{P}$ and $\mathrm{Cu}-30 \mathrm{Zn}-0.1 \mathrm{P}-0.5 \mathrm{Fe}$ alloys (all compositions are in weight percent) were prepared by induction vacuum melting and then hot rolling to eliminate some casting defects and obtain a homogenous and refined microstructure. The two alloy plates were then room temperature rolled with a total thickness reduction by $87 \%$ in several passes. The thickness reduction for each pass was about $10 \%$ and an annealing treatment at $773 \mathrm{~K}$ for $1 \mathrm{~h}$ was employed when the reduction accumulated at around 50\%. Rolling experiments were conducted on a S815E2 rolling mill with a roll diameter of $420 \mathrm{~mm}$ and rolling speed of $0.436 \mathrm{~m} / \mathrm{s}$. The cold rolled samples were then 
isothermally annealed at $573 \mathrm{~K}$ for different times ranging from 10 to $36000 \mathrm{~s}$ and then immediately quenched in water.

The Vickers hardness tests were measured at room temperature under a load of 1000 $\mathrm{g}$ for a loading period of $30 \mathrm{~s}$. At least 9 measurements are made in each case to obtain an average value. Microstructure characterization were all performed primarily on the mid-thickness rolling plane (containing RD and TD) by using optical microscope (OM), scanning electron microscopy (SEM, FEI Quanta ${ }^{\mathrm{TM}} 650$ FEG) equipped with a TSL OIM $^{\text {TM }}$ EBSD system and transmission electron microscopy (TEM, FEI Tecnai $\mathrm{G}^{2} 20$ ). Surfaces for OM observations were mechanically polished and then etched in a mixture of $12.5 \mathrm{~g}$ ferric chloride, $12.5 \mathrm{ml}$ chlorhydric acid and $50 \mathrm{ml}$ distilled water. Samples for the EBSD examinations were electropolished using an electrolyte of $70 \%$ phosphoric acid and $30 \%$ distilled water. Thin foils made for TEM observation were prepared through a conventional jet polishing technique in a solution of $25 \%$ nitric acid and $75 \%$ methanol at a temperature below -30 degree Celsius. To improve the reliability of the EBSD data, small grains comprising three or fewer pixels were automatically removed from the maps using the grain-dilation option and the map is slightly cleared. Furthermore, to eliminate spurious boundaries caused by orientation noise, a lower limit boundary-misorientation cutoff of $2^{\circ}$ was used. A $15^{\circ}$ criterion was used to differentiate low-angle boundaries (LABs) and high-angle boundaries (HABs). Grain size was quantified by the determination of the area of each grain and the calculation of its circle-equivalent diameter.

\section{Results and Discussion}

\subsection{Hardness behavior}

Vickers hardness-time curves of $\mathrm{Cu}-30 \mathrm{Zn}-0.1 \mathrm{P}-0.5 \mathrm{Fe}$ and $\mathrm{Cu}-30 \mathrm{Zn}-0.1 \mathrm{P}$ alloys 
during annealing at $573 \mathrm{~K}$ are presented in Fig.1. Three stages can be observed in both curves. With the addition of $\mathrm{Fe}$, higher initial hardness can be detected in $\mathrm{Cu}-30 \mathrm{Zn}-0.1 \mathrm{P}-0.5 \mathrm{Fe}$ alloy. Then recovery dominates at the beginning of annealing and small increase of hardness can be seen in both alloys (Stage I), which is frequently referred to as "anneal hardening". This phenomenon has been largely reported and investigated in $\mathrm{Cu}$ alloys containing different alloying elements ( $\mathrm{Zn}, \mathrm{Al}, \mathrm{Au}, \mathrm{Ga}, \mathrm{Pd}, \mathrm{Mn}$, Si) [17-22]. As reported in these papers, solute atoms migrate during annealing and then settle down segregating and locking to lattice defects (dislocations, stacking faults, etc.) introduced by prior cold working, which is analogous to the formation of Cottrel atmospheres in interstitial solid solution during recovery [17-22]. Thus, for the extra addition of Fe, more apparent increase in hardness is observed: the value of hardness is enhanced from $246 \mathrm{Hv}$ to $257 \mathrm{Hv}$ in $\mathrm{Cu}-30 \mathrm{Zn}-0.1 \mathrm{P}-0.5 \mathrm{Fe}$ alloy when that is increased from $233 \mathrm{Hv}$ to $241 \mathrm{Hv}$ in $\mathrm{Cu}-30 \mathrm{Zn}-0.1 \mathrm{P}$ alloy. Then, dramatic decrease due to recrystallization (Stage II) begins in $\mathrm{Cu}-30 \mathrm{Zn}-0.1 \mathrm{P}-0.5 \mathrm{Fe}$ and $\mathrm{Cu}-30 \mathrm{Zn}-0.1 \mathrm{P}$ alloys at around 500s and 100s, respectively, and the former alloy showed better thermal stability. Afterwards, decrease in hardness slows down at around $3600 \mathrm{~s}$ and $10800 \mathrm{~s}$, respectively (Stage III). Compared to $\mathrm{Cu}-30 \mathrm{Zn}-0.1 \mathrm{P}$ alloy, the decrease in hardness of $\mathrm{Cu}-30 \mathrm{Zn}-0.1 \mathrm{P}-0.5 \mathrm{Fe}$ alloy experiences a two-step slowdown before the hardness reaches a steady state, which might be related to the second phase particles formed with the addition of Fe. And a higher value of $157 \mathrm{Hv}$ is obtained after the long-time annealing treatment, which is enhanced by about $20 \%$ compared to that in $\mathrm{Cu}-30 \mathrm{Zn}-0.1 \mathrm{P}$ alloy. It can be concluded from the curves that $\mathrm{Cu}-30 \mathrm{Zn}-0.1 \mathrm{P}$ alloy is strengthened before and after annealing and show better thermal stability with the addition of Fe. These kinds of enhancement may be related to microstructural 
differences caused by the addition of Fe, which will be discussed later on.

\subsection{Microstructure development under annealing}

Fig. 2 shows the OM images of $\mathrm{Cu}-30 \mathrm{Zn}-0.1 \mathrm{P}-0.5 \mathrm{Fe}(\mathrm{a}, \mathrm{b})$ and $\mathrm{Cu}-30 \mathrm{Zn}-0.1 \mathrm{P}$ alloys (c, d) after cold rolling and subsequent annealing for $10800 \mathrm{~s}$ at $573 \mathrm{~K}$. It is clear that fewer deformation bands can be seen in the cold rolled $\mathrm{Cu}-30 \mathrm{Zn}-0.1 \mathrm{P}-0.5 \mathrm{Fe}$ alloy with the presence of extra particles (see Fig. 2a). Unlike $\mathrm{Cu}-30 \mathrm{Zn}-0.1 \mathrm{P}-0.5 \mathrm{Fe}$ alloy, frequent appearance of deformation bands is found in $\mathrm{Cu}-30 \mathrm{Zn}-0.1 \mathrm{P}$ alloy, some of which intersected each other (as marked by circles in Fig. 2c), and ultrafine grains with a size of $2-5 \mu \mathrm{m}$ are found at these intersections, which means dynamic recovery occurs during rolling. With the addition of $\mathrm{Fe}$, however, few deformation bands are observed and hardly ultrafine grains can be found, which means dynamic recovery is inhibited compared to $\mathrm{Cu}-30 \mathrm{Zn}-0.1 \mathrm{P}$ alloy. This may be related to the uniformly dispersed fine particles existed in that alloy before and after annealing (see Figs. 2a and 2b). Considering the content ratio of $\mathrm{Fe}$ and $\mathrm{P}$ added in the alloy, these particles should be $\mathrm{Fe}_{2} \mathrm{P}$ and/or $\mathrm{Fe}_{3} \mathrm{P}$ particles. Corresponding TEM images for both alloys are shown in Fig. 3 after annealing for $10800 \mathrm{~s}$, respectively. It can be seen that there is a uniform distribution of very fine particles lying within grains and at grain boundaries with the addition of Fe and the size of second phase particles is about $50 \mathrm{~nm} \sim 300 \mathrm{~nm}$ (Fig. 3a). In addition, the dislocation density in $\mathrm{Cu}-30 \mathrm{Zn}-0.1 \mathrm{P}-0.5 \mathrm{Fe}$ alloy is higher and the grains size is smaller and more uniform after annealing for 10800 s. To find out more microstructure details in $\mathrm{Cu}-30 \mathrm{Zn}-0.1 \mathrm{P}-0.5 \mathrm{Fe}$ alloy, selected area electron diffraction (SAED) patterns of the matrix and the particles are given (Figs. 3c and 3d), respectively. By calculating the angle and distance between two adjacent transmission spots and diffraction spots, it can be known that the diffraction pattern of the matrix is [110] zone 
axis of the face-centered cubic (fcc) crystal, i.e. the $\alpha-\mathrm{Cu}$ matrix. Thus, the main difference in microstructure after the addition of Fe elements is the presence of second phase particles. It then can be concluded that these particles should be responsible for any difference in deformation and annealing behaviors of $\mathrm{Cu}-30 \mathrm{Zn}-0.1 \mathrm{P}-0.5 \mathrm{Fe}$ alloy. Fig. 3d represents the SAED pattern of these particles. By using the same calibration method, the diffraction pattern is [02 $\overline{2} 3$ ] zone axis of the hexagonal crystal. By calculating the SAED pattern of particles, the lattice constants are $\mathrm{a}=\mathrm{b}=0.59 \mathrm{~nm}$ and $\mathrm{c}$ $=0.34 \mathrm{~nm}$, which is very close to the lattice constants of $\mathrm{Fe}_{2} \mathrm{P}(\mathrm{a}=\mathrm{b}=0.58660 \mathrm{~nm}, \mathrm{c}=$ $0.34563 \mathrm{~nm}$ ) [23]. It can be therefore confirmed that these particles observed in $\mathrm{Cu}-30 \mathrm{Zn}-0.1 \mathrm{P}-0.5 \mathrm{Fe}$ alloy are $\mathrm{Fe}_{2} \mathrm{P}$ particles.

Typical OIM maps of $\mathrm{Cu}-30 \mathrm{Zn}-0.1 \mathrm{P}-0.5 \mathrm{Fe}$ and $\mathrm{Cu}-30 \mathrm{Zn}-0.1 \mathrm{P}$ alloys evolved during annealing for $100 \mathrm{~s}$ (at around the beginning of recrystallization), $1800 \mathrm{~s}$ and $10800 \mathrm{~s}$ (at around the end of recrystallization) are shown in Fig. 4. Different colors indicate different crystallographic orientations as defined in the inverse pole figure, and lines indicate various boundaries, i.e. blue and black lines represent LABs and HABs, respectively, while red lines represent $\Sigma 3$ twin boundaries $\left(60^{\circ}<111>\right)$. Changes in average grain size and misorientation angle during annealing are concluded in Fig. 5. For $\mathrm{Cu}-30 \mathrm{Zn}-0.1 \mathrm{P}$ alloy, similar trends can be seen in the variation of average grain size and misorientation angle and corresponds to the variation of the hardness in Fig. 1 and can be divided into three stages: slow growth stage, sharp growth stage and the steady growth stage, representing the three stages of restoration: recovery, recrystallization and grain growth [24]. However, with the addition of Fe, when the average misorientation angle changes in the same way, recrystallized grains with initial smaller sizes in $\mathrm{Cu}-30 \mathrm{Zn}-0.1 \mathrm{P}-0.5 \mathrm{Fe}$ alloy grow in a much slower pace during annealing (which also 
confirms that thermal stability of $\mathrm{Cu}-30 \mathrm{Zn}-0.1 \mathrm{P}-0.5 \mathrm{Fe}$ alloy is enhanced). It should also be noted that the sharp growth stage is delayed and the average misorientation angle of $\mathrm{Cu}-30 \mathrm{Zn}-0.1 \mathrm{P}-0.5 \mathrm{Fe}$ alloy is always lower and grows more slowly, especially for the first $100 \mathrm{~s}$, when recovery dominates. Misorientation distribution details for both alloys at different annealing times are given in Fig. 6. As shown, during the first 100s, the fraction of LABs $\left(2^{\circ}-15^{\circ}\right)$ dominates in both alloys with lots of dislocation accumulations remaining. With annealing time increasing, the fraction of $\mathrm{HABs}\left(15^{\circ}-\right.$ $65^{\circ}$ ) increases and that of LABs decreases in both alloys but at a more slowly rate in $\mathrm{Cu}-30 \mathrm{Zn}-0.1 \mathrm{P}-0.5 \mathrm{Fe}$ alloy. It is worth noting that there are peaks around $60^{\circ}$ in almost all the distribution charts. This phenomenon can be attributed the presence of $\Sigma 3$ twin boundaries, which happens on the $\{111\}$ plane with a misorientation angle of $60^{\circ} . \Sigma 3$ twins are known as annealing twins commonly observed during processes of recrystallization and grain growth in $\mathrm{Cu}$ alloys [24 - 27]. There is a big difference in the fraction of $\Sigma 3$ twin boundaries between the two alloys and fewer $\Sigma 3$ twin boundaries are detected in $\mathrm{Cu}-30 \mathrm{Zn}-0.1 \mathrm{P}-0.5 \mathrm{Fe}$ alloy. This difference becomes larger as annealing proceeds. The formation of $\Sigma 3$ twin boundaries are hindered in $\mathrm{Cu}-30 \mathrm{Zn}-0.1 \mathrm{P}-0.5 \mathrm{Fe}$ alloy. Also, there is a positive correlation between the speed of grain boundary migration and the emergence of these twins [24, 25, 27], so it can be further illustrated the $\mathrm{Fe}_{2} \mathrm{P}$ precipitates can hinder the migration of grain boundaries. Thus, the addition of Fe and resulting $\mathrm{Fe}_{2} \mathrm{P}$ particles might have a great effect on the whole restoration process: the $\mathrm{Fe}_{2} \mathrm{P}$ precipitates firstly disturb dislocation accumulations from re-arranging or transforming into dislocation-free substructures with $\mathrm{HABs}$ and as a result, recrystallization is delayed. Also, due to the pinning effect of second phase particles, boundary migration is inhibited and grain growth is slowed down. 
Kernel average misorientation (KAM), one of the functions of OIM, shows the distribution of local misorientation based on a KAM between neighbors on the scan grid. Based on EBSD data, it is a tool in OIM analysis indicating geometrically necessary dislocations (GNDs) density and strain related energy stored in different areas, and vice versa [28 - 30]. The relationship between dislocation density and energy stored [30]:

$$
\begin{aligned}
& \rho=\alpha \theta /(\mathrm{bd}) \\
& \mathrm{E}=0.5 \alpha \rho \mathrm{Gb}^{2} \approx \alpha \theta \mathrm{Gb} /(2 \mathrm{~d})
\end{aligned}
$$

Where $\alpha$ is a constant which depends on the geometry of the dislocation arrangement, $\mathrm{b}$ is Burgers vector, $\theta$ is the value of KAM, $d$ is step size for the EBSD analysis, $\rho$ is dislocation density and $\mathrm{E}$ is stored energy per unit volume, $\mathrm{G}$ is the shear modulus. Generally, KAM is high in deformed grains while low in recrystallized grains [30]. The KAM distribution maps of both alloys are given in Fig. 7. Each color represent specific KAM range here, given in the bottom in the Figure. Accordingly, Blue with a KAM $\theta$ from $0^{\circ}$ to $1^{\circ}$ means the lowest local dislocation density areas while the red with a KAM $\theta$ from $4^{\circ}$ to $5^{\circ}$ represents the highest. Figs. 7 a and $7 \mathrm{~d}$ show the cold rolled specimens where lots of areas in green to red with higher KAM are found. But blue areas with low KAM expand with the increase of annealing time. Areas in blue in $\mathrm{Cu}-30 \mathrm{Zn}-0.1 \mathrm{P}$ alloy are wider than that in $\mathrm{Cu}-30 \mathrm{Zn}-0.1 \mathrm{P}-0.5 \mathrm{Fe}$ alloy but KAM in $\mathrm{Cu}-30 \mathrm{Zn}-0.1 \mathrm{P}-0.5 \mathrm{Fe}$ alloy is more evenly distributed. A quantitative KAM distribution is concluded in Fig. 8. It is apparent that the peak positions shift to lower KAM value but a higher and more concentrated peak is obtained with annealing time for both alloys. The KAM corresponding to peak position is always higher and the peak is more scattered in $\mathrm{Cu}-30 \mathrm{Zn}-0.1 \mathrm{P}-0.5 \mathrm{Fe}$ alloy. This phenomenon might be related to a higher dislocation density remained in the annealed $\mathrm{Cu}-30 \mathrm{Zn}-0.1 \mathrm{P}-0.5 \mathrm{Fe}$ alloy (see Fig. 3d) 
and $\mathrm{Fe}_{2} \mathrm{P}$ particles should be the main cause. As known, the most effective way to eliminate stored dislocation accumulations and strain energy is recrystallization [24]. The lower KAM is, the lower dislocation density and strain energy stored and the more fully recrystallization proceeds. On the other hand, higher KAM corresponds to higher dislocation density and higher energy unreleased. At annealing time of $10800 \mathrm{~s}$, though with almost the same peak KAM position, higher number fraction at the peak was remained in the alloy with the addition of Fe, which means that recrystallization restoration is slowed down in this alloy.

Now let's discuss about the enhanced hardness performance in $\mathrm{Cu}-30 \mathrm{Zn}-0.1 \mathrm{P}-0.5 \mathrm{Fe}$ alloy based on microstructural development. Considering the materials and deformation processes, several strengthening mechanisms in $\mathrm{Cu}-30 \mathrm{Zn}-0.1 \mathrm{P}-0.5 \mathrm{Fe}$ alloy can be proposed to draw a conclusion: solid solution strengthening, second phase strengthening and grain boundary strengthening. Baker $\mathrm{H}$ et al. [31] show that the solubility of $\mathrm{Fe}$ in $\mathrm{Cu}$ at room temperature is less than $0.0004 \%$, which means that $\mathrm{Fe}$ is almost insoluble in $\mathrm{Cu}$. As a result, the solid solution strengthening effect can be ignored. According to the difference in microstructures, it can be inferred that the main mechanisms responsible for the strengthening are particles strengthening mechanism due to the dispersed second phase particles and grain boundary strengthening mechanism with fine grains in $\mathrm{Cu}-30 \mathrm{Zn}-0.1 \mathrm{P}-0.5 \mathrm{Fe}$ alloy. It's worth noting that extra strengthening effects of dislocation substructures introduced by the particles should not be neglect, since there are still some differences in these substructures between two alloys after being annealed for $10800 \mathrm{~s}$, as seen from the TEM images and KAM results. 


\subsection{Microtextural changes during annealing}

Textures developed in both cold-rolled alloys and their evolution during annealing were studied in this section. Fig. 9 shows distributions of the typical texture components of $\mathrm{Cu}-30 \mathrm{Zn}-0.1 \mathrm{P}-0.5 \mathrm{Fe}$ and $\mathrm{Cu}-30 \mathrm{Zn}-0.1 \mathrm{P}$ alloys annealed at $573 \mathrm{~K}$ for different times. The corresponding crystallographic faces and directions of these components are listed in Table 1. These texture components can be classified into two types: rolling texture and recrystallization texture. Changes in area fraction of main texture components and sum area fraction of each type of textures in $\mathrm{Cu}-30 \mathrm{Zn}-0.1 \mathrm{P}-0.5 \mathrm{Fe}$ and $\mathrm{Cu}-30 \mathrm{Zn}-0.1 \mathrm{P}$ alloys are concluded as a function of annealing time in Fig. 10. As shown in Fig. 10, with the increase of annealing time, the fraction of recrystallization textures increases and that of rolling textures decreases. Moreover, more remnant of rolling textures is found in $\mathrm{Cu}-30 \mathrm{Zn}-0.1 \mathrm{P}-0.5 \mathrm{Fe}$ alloys. This shows again that recrystallization is inhibited with the addition of $\mathrm{Fe}$, where $\mathrm{Fe}_{2} \mathrm{P}$ is responsible.

From Fig. 9 and Fig. 10, it is noted that both alloys under annealing are mainly comprised of Brass (red), Brass-R (cyan) and $(55 ; 30 ; 0)$ (pink) textures (as fractions of other rolling textures were small after annealing and little Cube-R (green) texture can be found in $\mathrm{Cu}-30 \mathrm{Zn}-0.1 \mathrm{P}-0.5 \mathrm{Fe}$ alloy, seen from Figs. 10a and b). At beginning of annealing, Brass texture dominates in both alloys. For the first $100 \mathrm{~s}$, fractions of $\{011\}<211>$ Brass, $\{236\}<385>$ Brass-R and $(55 ; 30 ; 0)$ texture in $\mathrm{Cu}-30 \mathrm{Zn}-0.1 \mathrm{P}-0.5 \mathrm{Fe}$ alloy are 33\%, 3\% and 3\% (Fig. 10a), respectively, while in $\mathrm{Cu}-30 \mathrm{Zn}-0.1 \mathrm{P}$ alloy are $20 \%, 5 \%$ and $6 \%$ (Fig. 10b). Then after annealed for $10800 \mathrm{~s}$, fractions of these three textures that are $9 \%, 22 \%$ and $12 \%$ in $\mathrm{Cu}-30 \mathrm{Zn}-0.1 \mathrm{P}-0.5 \mathrm{Fe}$ alloy (Fig. 10a), which are higher than those in $\mathrm{Cu}-30 \mathrm{Zn}-0.1 \mathrm{P}$ alloy (7\%, 17\% and 8\%, respectively) (Fig. 10b). Their correlation might be responsible for the special phenomenon that the sum 
fractions of these three components are always higher during annealing with the addition of Fe.

Brass texture is usually found as the dominant texture in the deformed microstructures and its formation can be accelerated when dislocation movements are under suppression in $\mathrm{Cu}$ alloys [27, 32 - 35] as in the present case with the addition of Fe in the $\mathrm{Cu}-30 \mathrm{Zn}-0.1 \mathrm{P}$ alloy. The pinning effect of dispersed particles on the dislocation movements in the $\mathrm{Cu}-30 \mathrm{Zn}-0.1 \mathrm{P}-0.5 \mathrm{Fe}$ alloy could result in more fraction of Brass texture in the deformed state compared with the deformed $\mathrm{Cu}-30 \mathrm{Zn}-0.1 \mathrm{P}$. Upon annealing, these microstructures with Brass type rolling textures would mostly transformed into Brass-R textures [34]. Besides, it is worth mentioning that the $(55 ; 30 ; 0)$ orientation, which is found as a recrystallization texture, is close to that of Brass texture and might also derive from orientation spread of the Brass component during annealing [33]. Therefore, it is reasonable to see that a larger amount of Brass- $\mathrm{R}$ texture and $(55 ; 30 ; 0)$ grains is obtained in the annealed $\mathrm{Cu}-30 \mathrm{Zn}-0.1 \mathrm{P}-0.5 \mathrm{Fe}$ alloy than in the annealed $\mathrm{Cu}-30 \mathrm{Zn}-0.1 \mathrm{P}$ one.

\section{Conclusions}

The effect of $\mathrm{Fe}$ addition in the $\mathrm{Cu}-30 \mathrm{Zn}-0.1 \mathrm{P}$ alloy on grain size and annealing behavior of brasses was studied and can be summarized as follows:

(1) Hardness was increased with dispersed second phase particles due to the addition of $\mathrm{Fe}$, whose main strengthening mechanisms are second phase strengthening and grain boundary strengthening.

(2) Due to the pinning effect of second phase particles on dislocation motion and boundary migration, recrystallization in $\mathrm{Cu}-30 \mathrm{Zn}-0.1 \mathrm{P}-0.5 \mathrm{Fe}$ alloy is hindered. Dislocation density decreases slowly, strain energy releases in a low speed and grains 
hardly grow during annealing. As a result, significant enhancement of thermal stability was found in the $\mathrm{Cu}-30 \mathrm{Zn}-0.1 \mathrm{P}-0.5 \mathrm{Fe}$ alloy.

(3) A higher fraction Brass texture component was seen in $\mathrm{Cu}-30 \mathrm{Zn}-0.1 \mathrm{P}-0.5 \mathrm{Fe}$ alloy after cold rolling. And high fractions of Brass-R and $(55 ; 30 ; 0)$ textures were obtained in $\mathrm{Cu}-30 \mathrm{Zn}-0.1 \mathrm{P}-0.5 \mathrm{Fe}$ alloy after annealing due to the correlation between Brass, Brass- $\mathrm{R}$ and $(55 ; 30 ; 0)$ textures.

\section{Acknowledgements}

The authors gratefully acknowledge support from the National Science Foundation of China (NO. 51174234).

\section{References}

[1] Kumar KS, Swygenhoven HV, Suresh S. Mechanical behavior of nanocrystalline metals and alloys. Acta Mater 2003;51:5743-5774.

[2] Gleiter H. Nanostructured materials: basic concepts and microstructure. Acta Mater 2000;48:1-29.

[3] Sauvage $\mathrm{X}$, Wetscher F, Pareige P. Mechanical alloying of $\mathrm{Cu}$ and $\mathrm{Fe}$ induced by severe plastic deformation of a Cu-Fe composite. Acta Mater 2005;53:2127-2135.

[4] Yamashita A, Horita Z, Langdon TG. Improving the mechanical properties of magnesium and a magnesium alloy through severe plastic deformation. Mater Sci Eng A 2001;300:142-147.

[5] Shangina DV, Bochvar NR, Dobatkin SV. The effect of alloying with hafnium on the thermal stability of chromium bronze after severe plastic deformation. J Mater Sci 2012;47:7764-7769. 
[6] Mazilkin AA, Myshlyaev MM. Microstructure and thermal stabilityof superplastic aluminium-lithium alloy after severe plastic deformation. J Mater Sci 2006;41:3767-3772.

[7] Nikulin I, Kipelova A, Malopheyev S, Kaibyshev R. Effect of second phase particles on grain refinement during equal-channel angular pressing of an $\mathrm{Al}-\mathrm{Mg}-\mathrm{Mn}$ alloy. Acta Mater 2012;60:487-497.

[8] Apps PJ, Bowen JR, Prangnell PB. The effect of coarse second-phase particles on the rate of grain refinement during severe deformation processing. Acta Mater $2003 ; 51: 2811-2822$

[9] Gazizov M, Malopheyev S, Kaibyshev R. The effect of second-phase particles on grain refinement during equal-channel angular pressing in an $\mathrm{Al}-\mathrm{Cu}-\mathrm{Mg}-\mathrm{Ag}$ alloy. $\mathrm{J}$ Mater Sci 2015;50:990-1005.

[10] Shi GD, Chen XH, Jiang H, Wang ZD, Tang H, Fan YQ. Strengthening mechanisms of Fe nanoparticles for single crystal Cu-Fe alloy. Mater Sci Eng A 2015;636:43-47.

[11] Stepanov ND, Kuznetsov AV, Salishchev GA, Khlebova NE, Pantsyrny VI. Evolution of microstructure and mechanical properties in $\mathrm{Cu}-14 \% \mathrm{Fe}$ alloy during severe cold rolling. Mater Sci Eng A 2013;564:264-272.

[12] Patchett JA, Abbaschian GJ. Grain refinement of copper by the addition of iron and by electromagnetic stirring. Metall Mater Trans B 1985;16:505-511.

[13] Ye YX, Yang XY, Liu CZ, Shen YZ, Zhang XK, Sakai T. Enhancement of strength and ductility of Cu-Sn-Zn alloy by iron addition. Mater Sci Eng A 2014;612:246-252.

[14] Aghaie-Khafri M, Mohebati-Jouibari A. Thermomechanical treatment of 70/30 brass containing iron impurity, J Mater Sci 2006;41(22):7585-7589.

[15] Verhoeven JD, Chueh SC, Gibson ED. Strength and conductivity of in situ Cu-Fe 
alloys. J Mater Sci 1989;24(5):1748-1752.

[16] Lu D, Wang J, Zeng W, Liu Y, Lu L, Sun B. Study on high-strength and high-conductivity Cu-Fe-P alloys. Mater Sci Eng A 2006;421:254-259.

[17] Bader M, Eldis GT, Warlimont $\mathrm{H}$. The mechanisms of anneal hardening in $\mathrm{Cu}-\mathrm{Al}$ alloys. Metall Trans A, 1976;7(2):249-255.

[18] Vitek JM, Warlimont H. The Mechanism of Anneal Hardening in Dilute Copper Alloys. Metall Mater Trans A 1979;10:1889-1992.

[19] Nestorović S, Marković D, Marković I. Influence of thermal cycling treatment on the anneal hardening effect of Cu-10Zn Alloy. J Alloy Compd, 2010;489:582-585.

[20] Marković I, Nestorović S, Markoli B, Premović M, Šturm S. Anneal hardening in cold rolled PM Cu-Au alloy. Mater Sci Eng A, 2016;658:393-399.

[21] Gong YL, Ren SY, Zeng SD, Zhu XK. Unusual hardening behaviour in heavily cryo-rolled $\mathrm{Cu}-\mathrm{Al}-\mathrm{Zn}$ alloys during annealing treatment. Mater Sci Eng A, 2016;659:165-171.

[22] Zhang XK, Yang XY, Chen W, Qin J, Fouse JP. Effect of stacking fault energy on mechanical properties and annealing behavior of brasses. J Alloy Compd 2016;679:400-407.

[23] Carlsson B, Gölin M, Rundqvist S. Determination of the homogeneity range and refinement of the crystal structure of $\mathrm{Fe}_{2} \mathrm{P}$. J Solid State Chem 1973;8:57-67.

[24] Humphreys FJ, Hatherly M. Recrystallization and Related Annealing Phenomena 2nd ed. Elsevier Ltd, Oxford; 2004.

[25] Mahajan S, Pande CS, Imam MA, Rath BB. Formation of annealing twins in f.c.c. crystals. Acta Mater 1997;45:2633-2638.

[26] Zhang XK, Yang XY, Chen W, Qin J, Fouse JP. Effects of rolling temperature and 
subsequent annealing on mechanical properties of ultrafine-grained $\mathrm{Cu}-\mathrm{Zn}-\mathrm{Si}$ alloy. Mater Charact 2015;106:100-107.

[27] Li HL, Hsu E, Szpunar J, Utsunomiya H, Sakai T. Deformation mechanism and texture and microstructure evolution during high-speed rolling of AZ31B Mg sheets. J Mater Sci 2008;43:7148-7156.

[28] Wright SI, Nowell MM, Field DP. A review of strain analysis using electron backscatter diffraction. Microsc Microanal 2011;17:316-329.

[29] Roy S, Sarkar A, Suwas S. On characterization of deformation microstructure in Boron modified Ti-6Al-4V alloy. Mate Sci and Eng A 2010;528:449-458.

[30] Takayama Y, Szpunar JA. Stored energy and Taylor factor relation in an Al-Mg-Mn alloy sheet worked by continuous cyclic bending. Mater Trans 2004;45:2316-2325.

[31] Baker H, Okamoto H. ASM handbook: alloy phase diagrams. ASM International. Materials Park;1992.

[32] Smallman RE, Green D. The dependence of rolling texture on stacking fault energy. Acta Metall 1964;12:145-154.

[33] Konkova T, Mironov S, Korznikov A, Semiatin SL. Annealing behavior of cryogenically-rolled copper. Mater Sci Eng A 2013;585:178-189.

[34] Sztwiertnia K. Recrystallization textures and the concept of oriented growth revisited. Mater Lett 2014;123:41-43.

[35] Konkova T, Mironov S, Korznikov A, Myshlyaev MM, Semiatin SL. Grain structure evolution during cryogenic rolling of alpha brass. J Alloy Compd 2015;629:140-147.

\section{Table caption}

Table 1 Several ideal rolling and recrystallization textures for face-centered cubic 
metals.

\section{Figure captions}

Fig. 1 Variations of Vickers hardness with annealing time at $573 \mathrm{~K}$ for $\mathrm{Cu}-30 \mathrm{Zn}-0.1 \mathrm{P}-0.5 \mathrm{Fe}$ and $\mathrm{Cu}-30 \mathrm{Zn}-0.1 \mathrm{P}$ alloys.

Fig. $2 \mathrm{OM}$ images of $\mathrm{Cu}-30 \mathrm{Zn}-0.1 \mathrm{P}-0.5 \mathrm{Fe}$ alloy (a) before and (b) after annealing and Cu-30Zn-0.1P alloy (c) before and (d) after annealing for $10800 \mathrm{~s}$.

Fig. 3 Microstructures of specimens annealed for 10800s: TEM images of (a) Cu-30Zn-0.1P-0.5Fe and (b) Cu-30Zn-0.1P alloys; (c) a [110] selected area electron diffraction (SAED) pattern of matrix and (d) second phase particles in (a).

Fig. 4 Typical OIM maps of $\mathrm{Cu}-30 \mathrm{Zn}-0.1 \mathrm{P}-0.5 \mathrm{Fe}$ and $\mathrm{Cu}-30 \mathrm{Zn}-0.1 \mathrm{P}$ alloys evolved during annealing at different holding times.

Fig. 5 Variation in average grain size and average misorientation angle of Cu-30Zn-0.1P-0.5Fe and Cu-30Zn-0.1P alloys with different annealing times.

Fig. 6 Misorientation angle distributions for ranges of $2-65^{\circ}$ of $\mathrm{Cu}-30 \mathrm{Zn}-0.1 \mathrm{P}-0.5 \mathrm{Fe}$ (a, b, c) and $\mathrm{Cu}-30 \mathrm{Zn}-0.1 \mathrm{P}$ alloys (d, e, f) annealed for different times.

Fig. 7 Kernel average misorientation maps of $\mathrm{Cu}-30 \mathrm{Zn}-0.1 \mathrm{P}-0.5 \mathrm{Fe}$ and $\mathrm{Cu}-30 \mathrm{Zn}-0.1 \mathrm{P}$ alloys with different annealing times.

Fig. 8 Kernel average misorientation distributions of $\mathrm{Cu}-30 \mathrm{Zn}-0.1 \mathrm{P}-0.5 \mathrm{Fe}$ and $\mathrm{Cu}-30 \mathrm{Zn}-0.1 \mathrm{P}$ alloys with different annealing times.

Fig. 9 Distributions of the main texture components within the OIM maps for Cu-30Zn-0.1P-0.5Fe and $\mathrm{Cu}-30 \mathrm{Zn}-0.1 \mathrm{P}$ alloys annealed for different times.

Fig. 10 Annealing time dependence of area fraction of main texture components $(a, b)$ and sum fraction of rolling and recrystallization textures (c, d) in $\mathrm{Cu}-30 \mathrm{Zn}-0.1 \mathrm{P}-0.5 \mathrm{Fe}$ and $\mathrm{Cu}-30 \mathrm{Zn}-0.1 \mathrm{P}$ alloys. 
Table 1 Several ideal rolling and recrystallization textures for face-centered cubic metals.

\begin{tabular}{cllllll}
\hline & & \multicolumn{3}{c}{ Euler angles (degree) } & \multicolumn{2}{c}{ Miller indices } \\
\multicolumn{1}{c}{ Texture types } & $\varphi_{1}$ & $\phi$ & $\varphi_{2}$ & $\begin{array}{l}\text { Rolling } \\
\text { plane }\end{array}$ & $\begin{array}{l}\text { Rolling } \\
\text { Direction }\end{array}$ \\
& Brass & 35 & 45 & 0 & $\{011\}$ & $\langle 211\rangle$ \\
\multirow{5}{*}{ Rolling textures } & Goss & 0 & 45 & 90 & $\{011\}$ & $\langle 100\rangle$ \\
& Cube & 0 & 0 & 0 & $\{001\}$ & $\langle 100\rangle$ \\
& Dillamore & 90 & 27 & 45 & $\{4 ; 4 ; 11\}$ & $\langle 11 ; 11 ; 8\rangle$ \\
& & & & & & \\
Recrystallization & & & & & & \\
textures & Cube-RD & 0 & 22 & 0 & $\{013\}$ & $\langle 100\rangle$ \\
& Brass-R & 80 & 31 & 35 & $\{236\}$ & $\langle 385\rangle$ \\
\hline
\end{tabular}


Fig. 1 Variations of Vickers hardness with annealing time at $573 \mathrm{~K}$ for $\mathrm{Cu}-30 \mathrm{Zn}-0.1 \mathrm{P}-0.5 \mathrm{Fe}$ and $\mathrm{Cu}-30 \mathrm{Zn}-0.1 \mathrm{P}$ alloys.

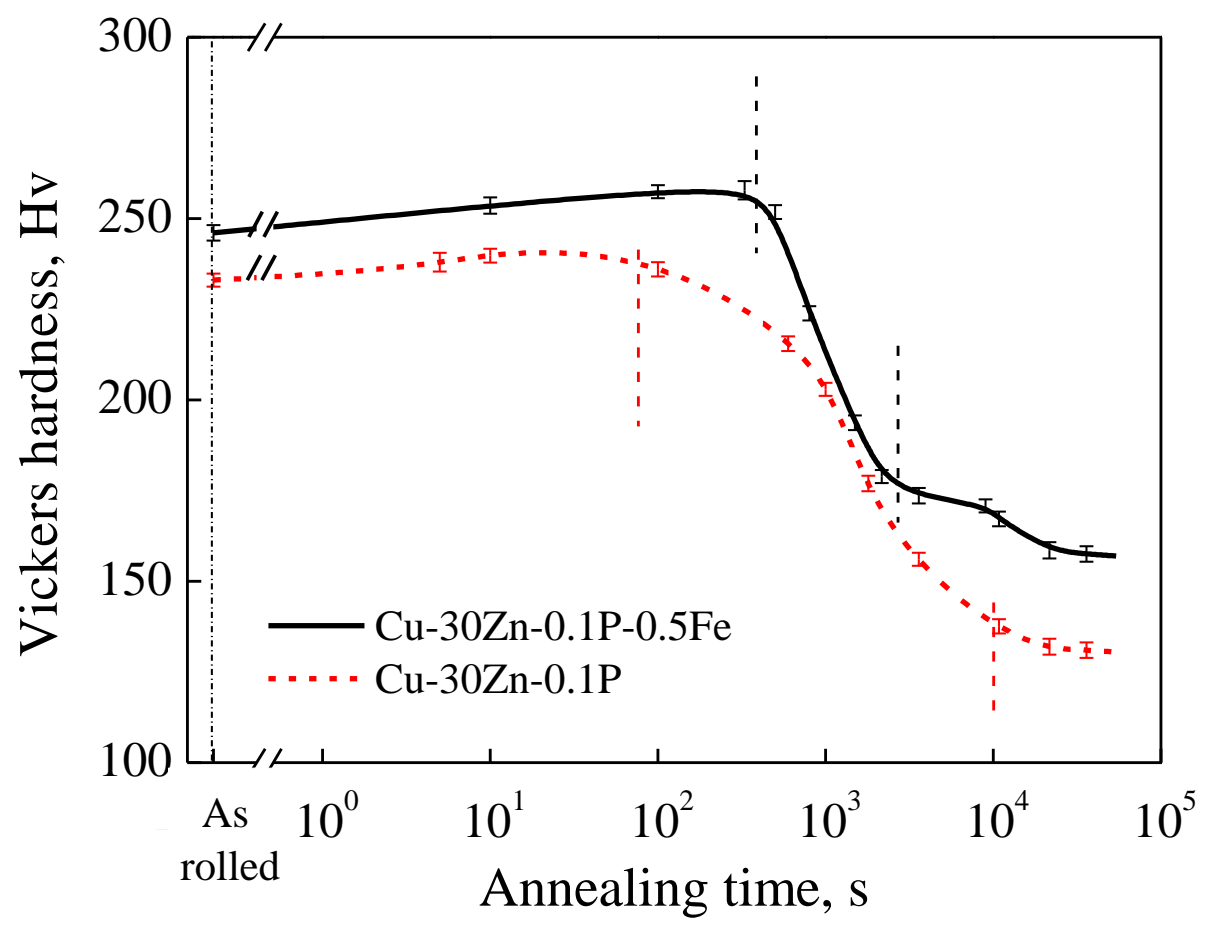


Fig. 2 OM images of Cu-30Zn-0.1P-0.5Fe alloy (a) before and (b) after annealing and

$\mathrm{Cu}-30 \mathrm{Zn}-0.1 \mathrm{P}$ alloy (c) before and (d) after annealing for $10800 \mathrm{~s}$.
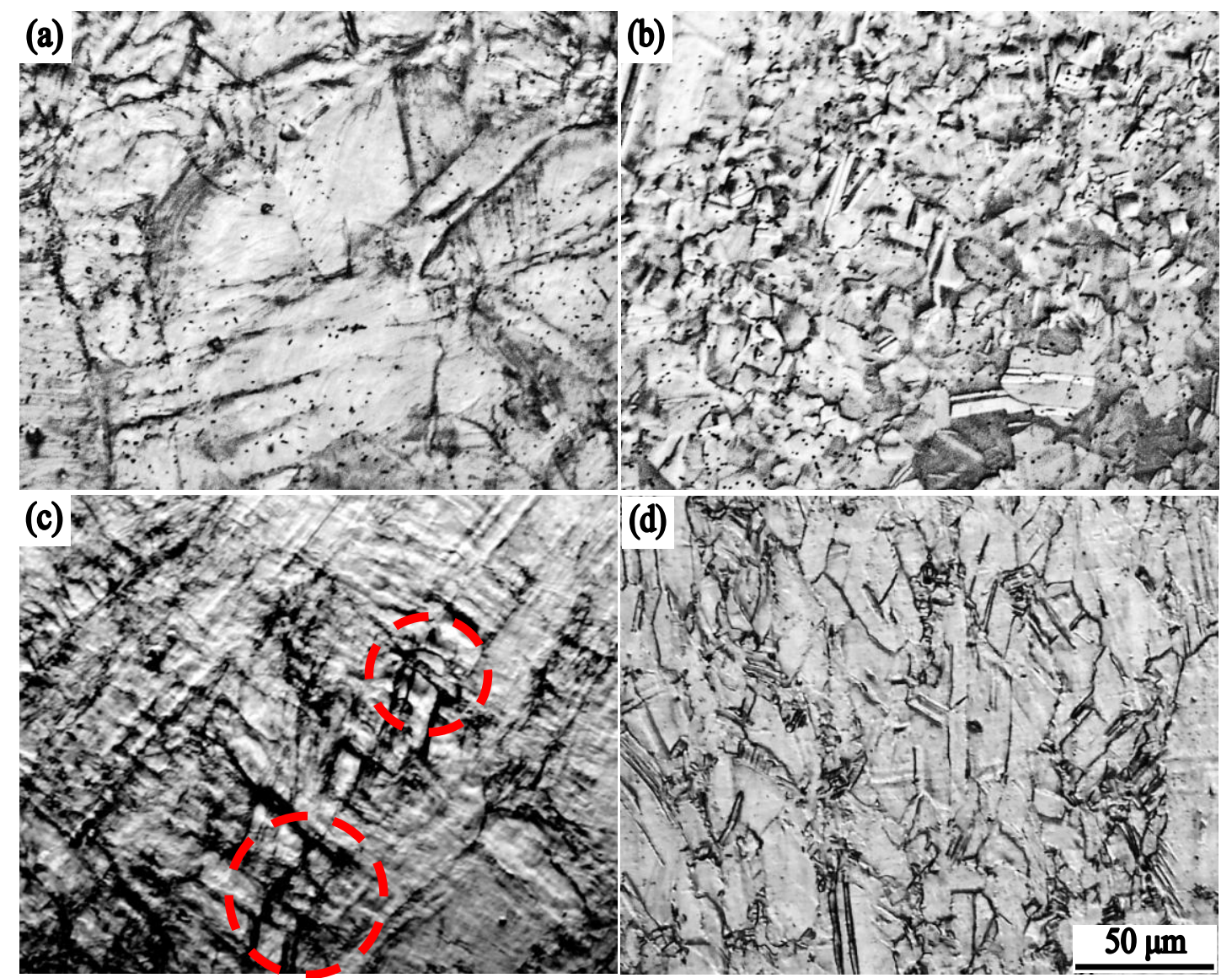
Fig. 3 Microstructures of specimens annealed for 10800 s: TEM images of (a) $\mathrm{Cu}-30 \mathrm{Zn}-0.1 \mathrm{P}-0.5 \mathrm{Fe}$ and (b) $\mathrm{Cu}-30 \mathrm{Zn}-0.1 \mathrm{P}$ alloys; (c) a [110] selected area electron diffraction (SAED) pattern of matrix and (d) second phase particles in (a).
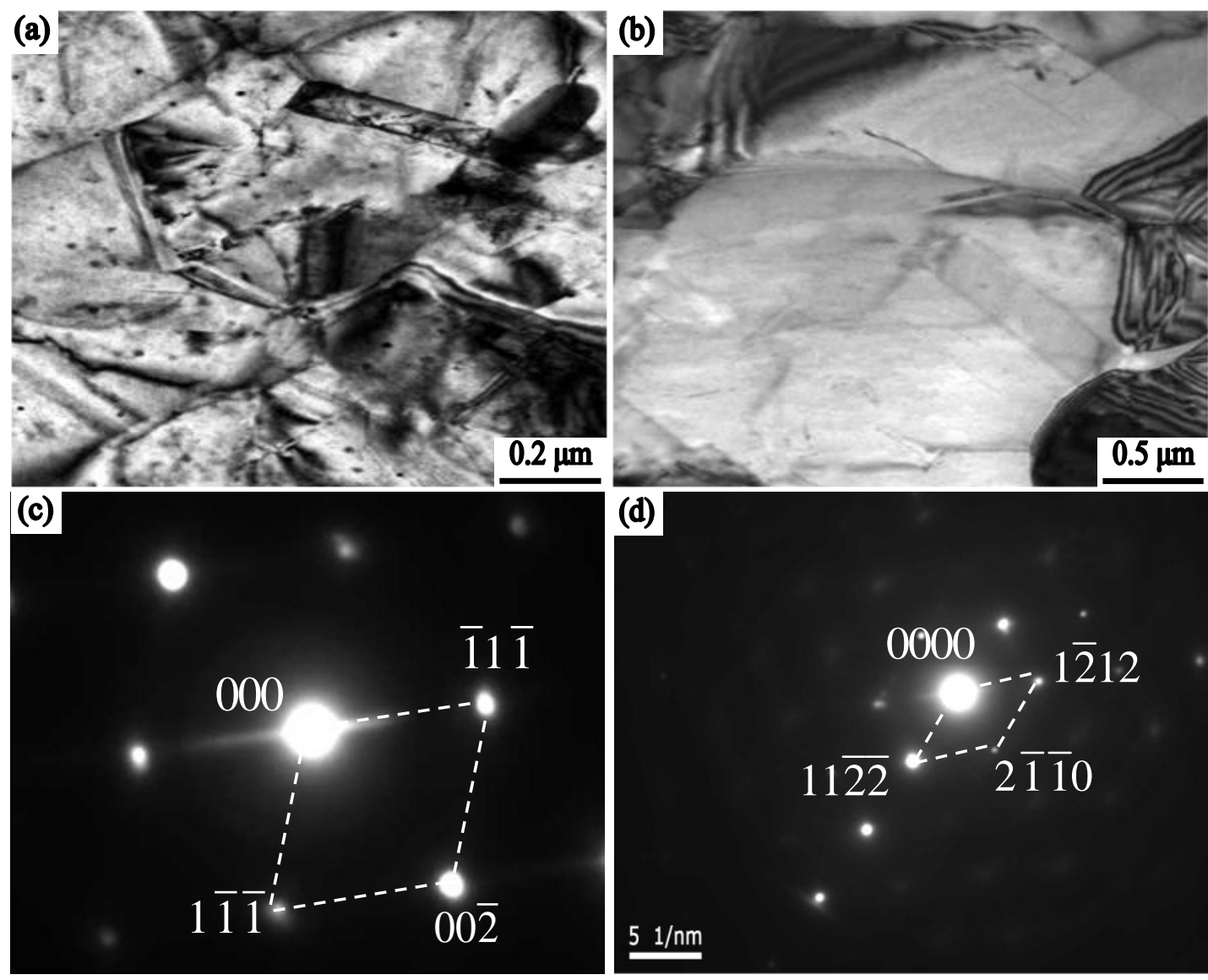
Fig. 4 Typical OIM maps of $\mathrm{Cu}-30 \mathrm{Zn}-0.1 \mathrm{P}-0.5 \mathrm{Fe}$ and $\mathrm{Cu}-30 \mathrm{Zn}-0.1 \mathrm{P}$ alloys evolved during annealing at different holding times.

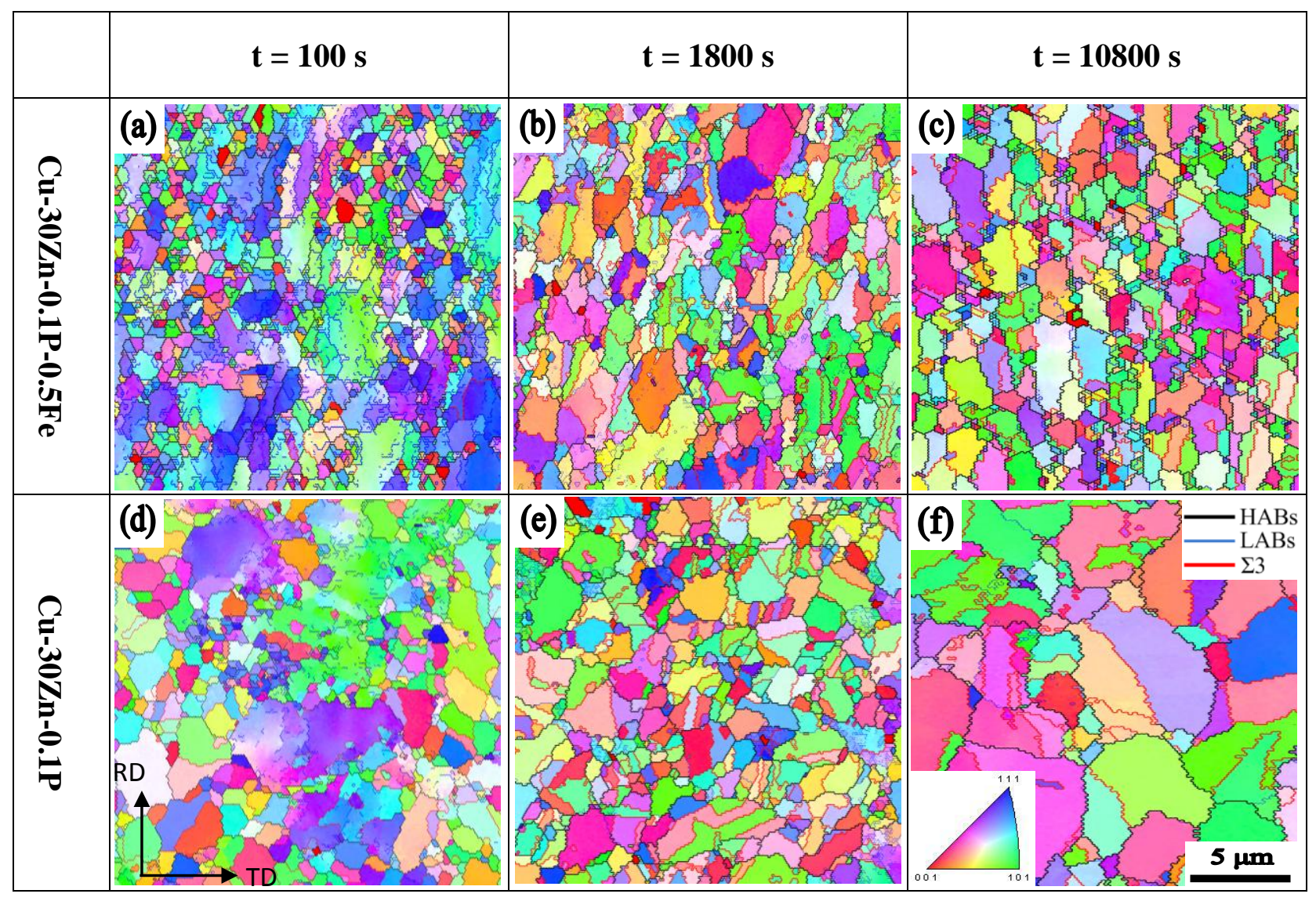


Fig. 5 Variation in average grain size and average misorientation angle of $\mathrm{Cu}-30 \mathrm{Zn}-0.1 \mathrm{P}-0.5 \mathrm{Fe}$ and $\mathrm{Cu}-30 \mathrm{Zn}-0.1 \mathrm{P}$ alloys with different annealing times.

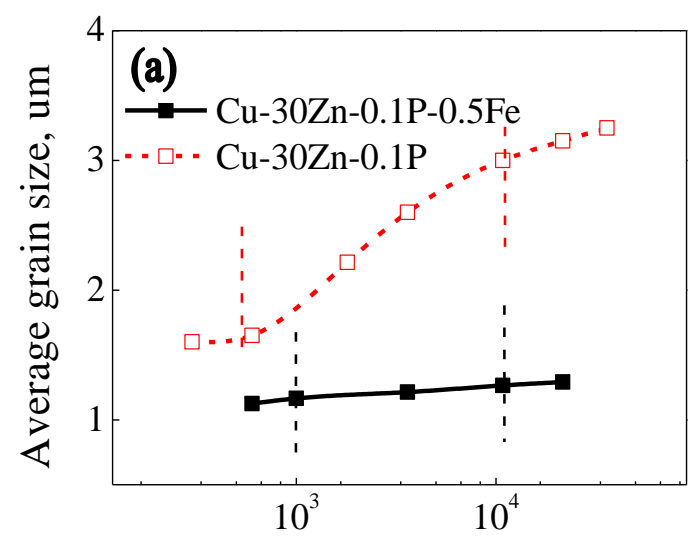

Annealing time, $\mathrm{s}$

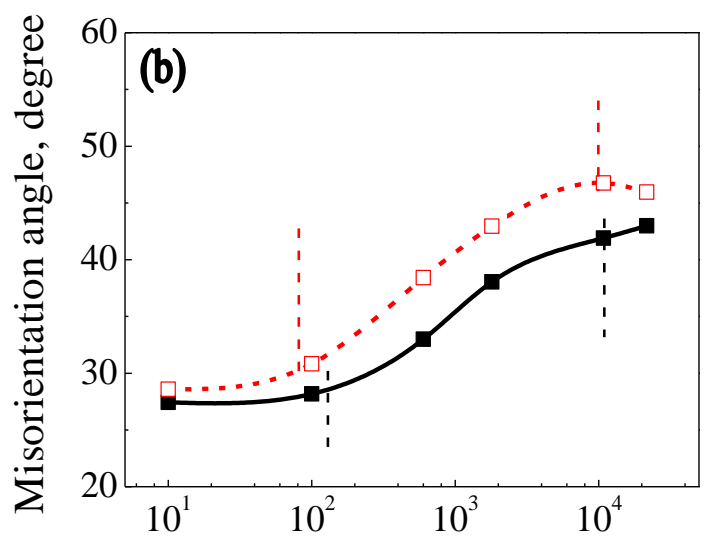

Annealing time, $s$ 
Fig. 6 Misorientation angle distributions for ranges of $2-65^{\circ}$ of $\mathrm{Cu}-30 \mathrm{Zn}-0.1 \mathrm{P}-0.5 \mathrm{Fe}$ (a, b, c) and Cu-30Zn-0.1P alloys (d, e, f) annealed for different times.

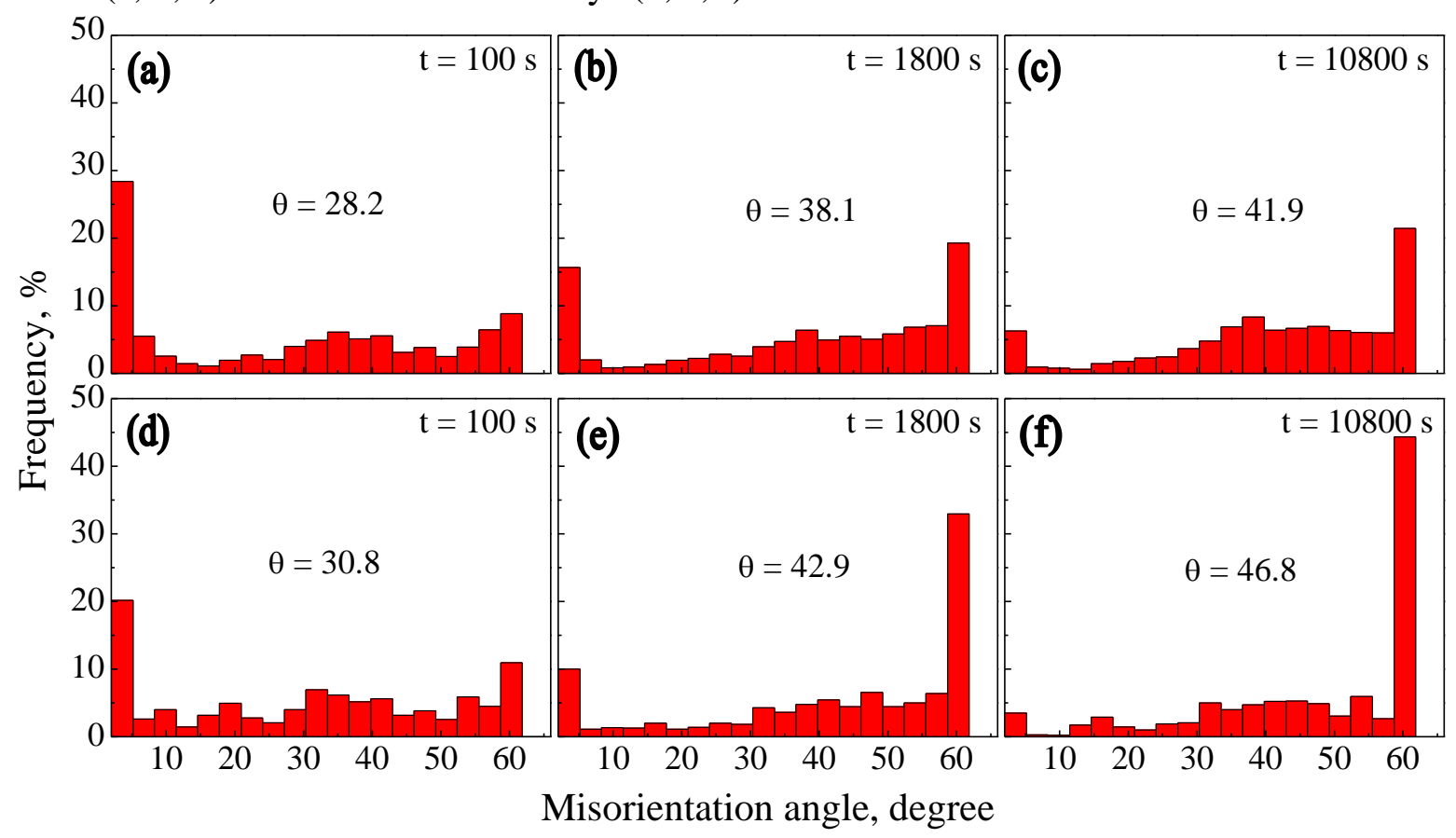


Fig. 7 Kernel average misorientation maps of $\mathrm{Cu}-30 \mathrm{Zn}-0.1 \mathrm{P}-0.5 \mathrm{Fe}$ and $\mathrm{Cu}-30 \mathrm{Zn}-0.1 \mathrm{P}$ alloys with different annealing times.

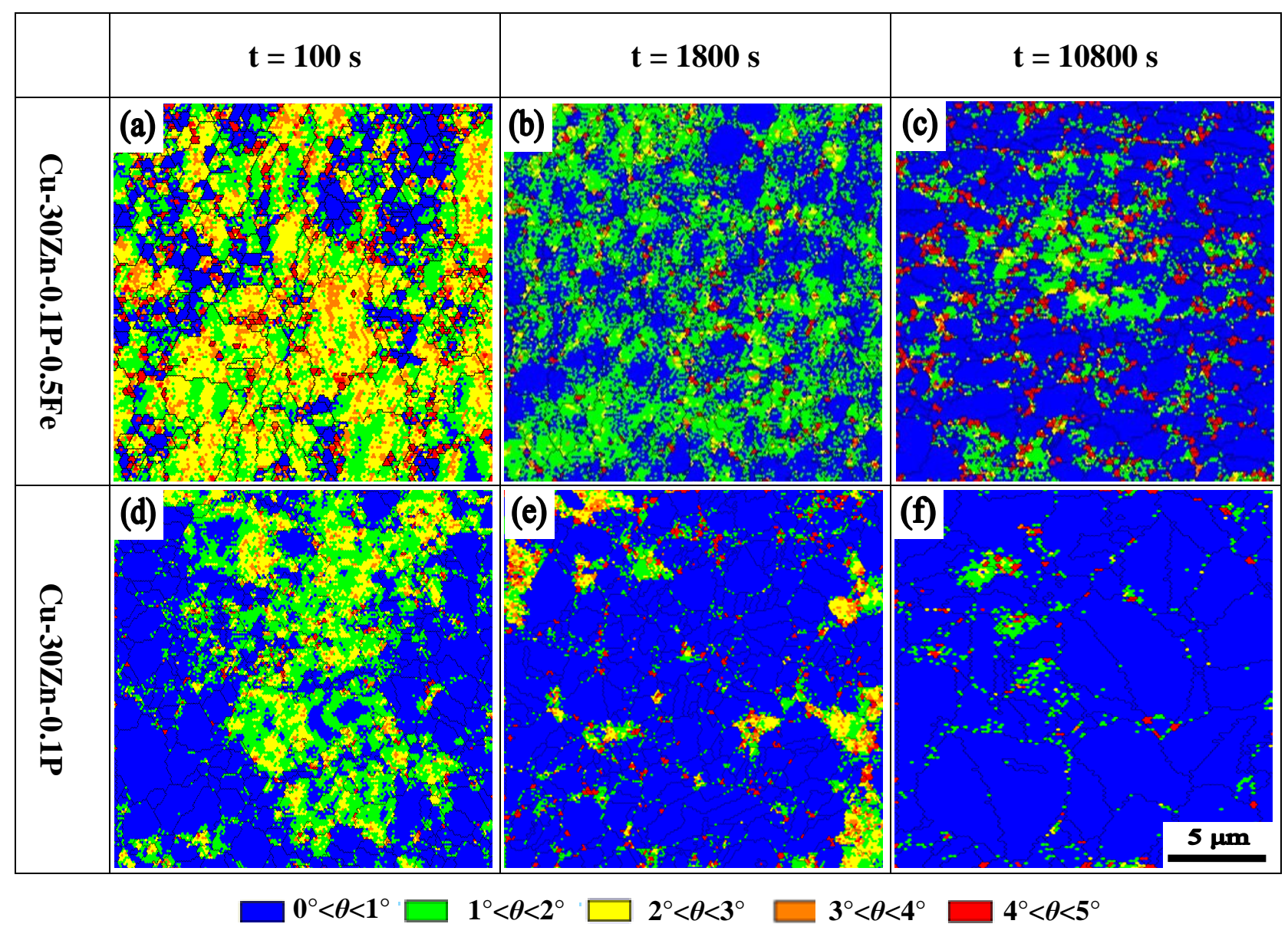


Fig. 8 Kernel average misorientation distributions of $\mathrm{Cu}-30 \mathrm{Zn}-0.1 \mathrm{P}-0.5 \mathrm{Fe}$ and $\mathrm{Cu}-30 \mathrm{Zn}-0.1 \mathrm{P}$ alloys with different annealing times.

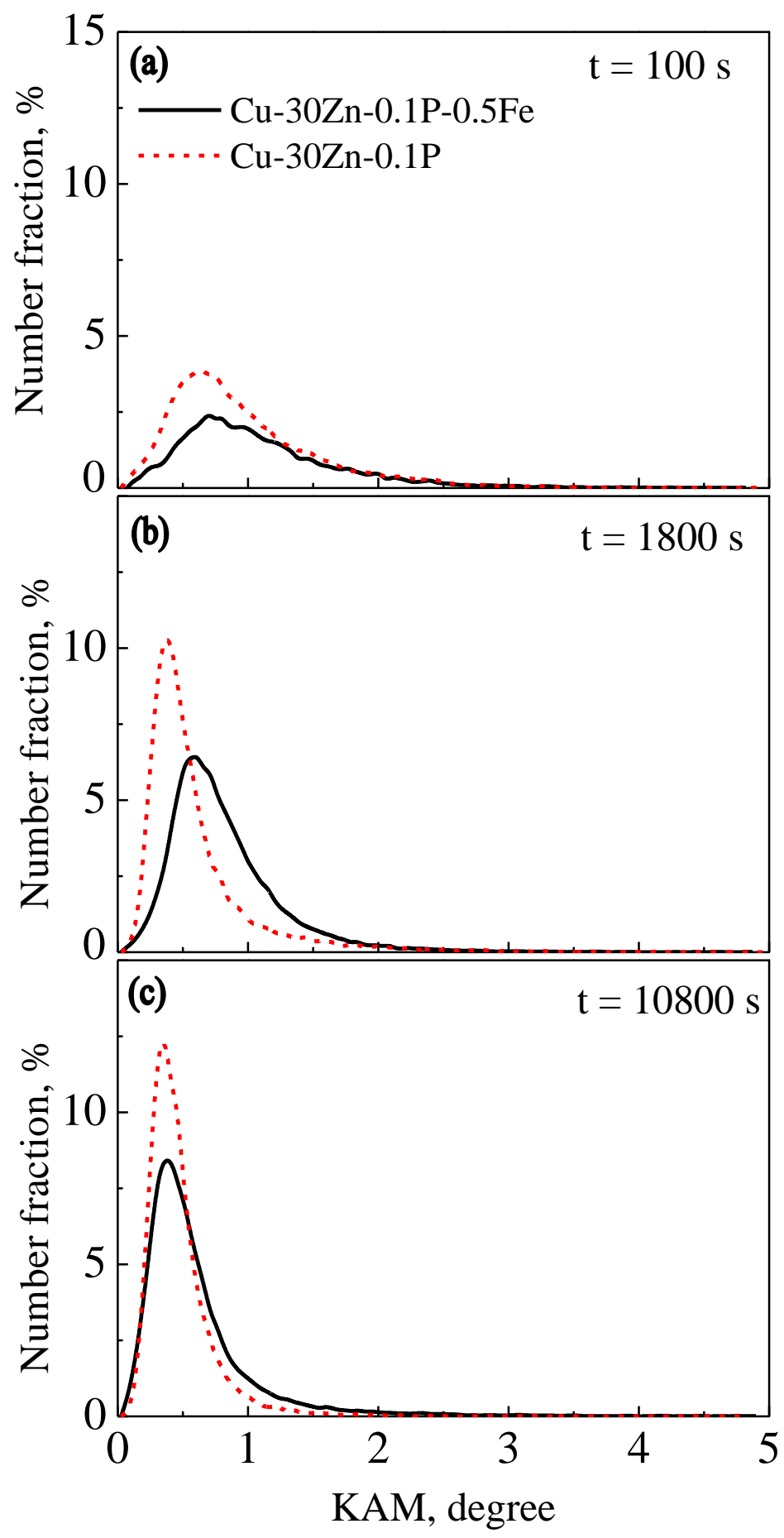


Fig. 9 Distributions of the main texture components within the OIM maps for Cu-30Zn-0.1P-0.5Fe and Cu-30Zn-0.1P alloys annealed for different times.

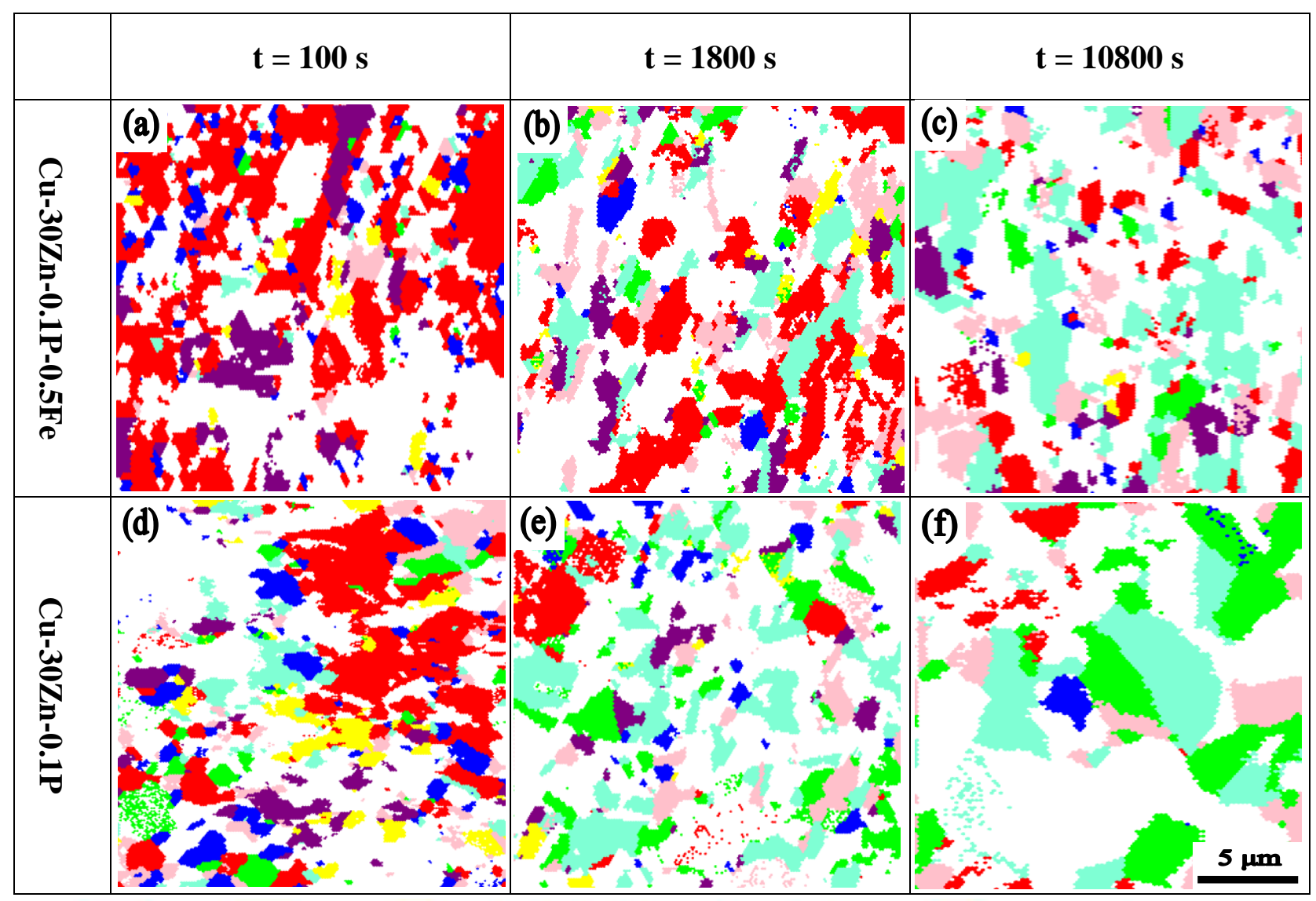

$\square$ Brass $\square$ Goss $\square$ Cube $\square$ Dillamore $\square(55 ; 30 ; 0) \square$ Cube - R $\square$ Brass - R 
Fig. 10 Annealing time dependence of area fraction of main texture components $(a, b)$ and sum fraction of rolling and recrystallization textures $(\mathrm{c}, \mathrm{d})$ in $\mathrm{Cu}-30 \mathrm{Zn}-0.1 \mathrm{P}-0.5 \mathrm{Fe}$ and $\mathrm{Cu}-30 \mathrm{Zn}-0.1 \mathrm{P}$ alloys.
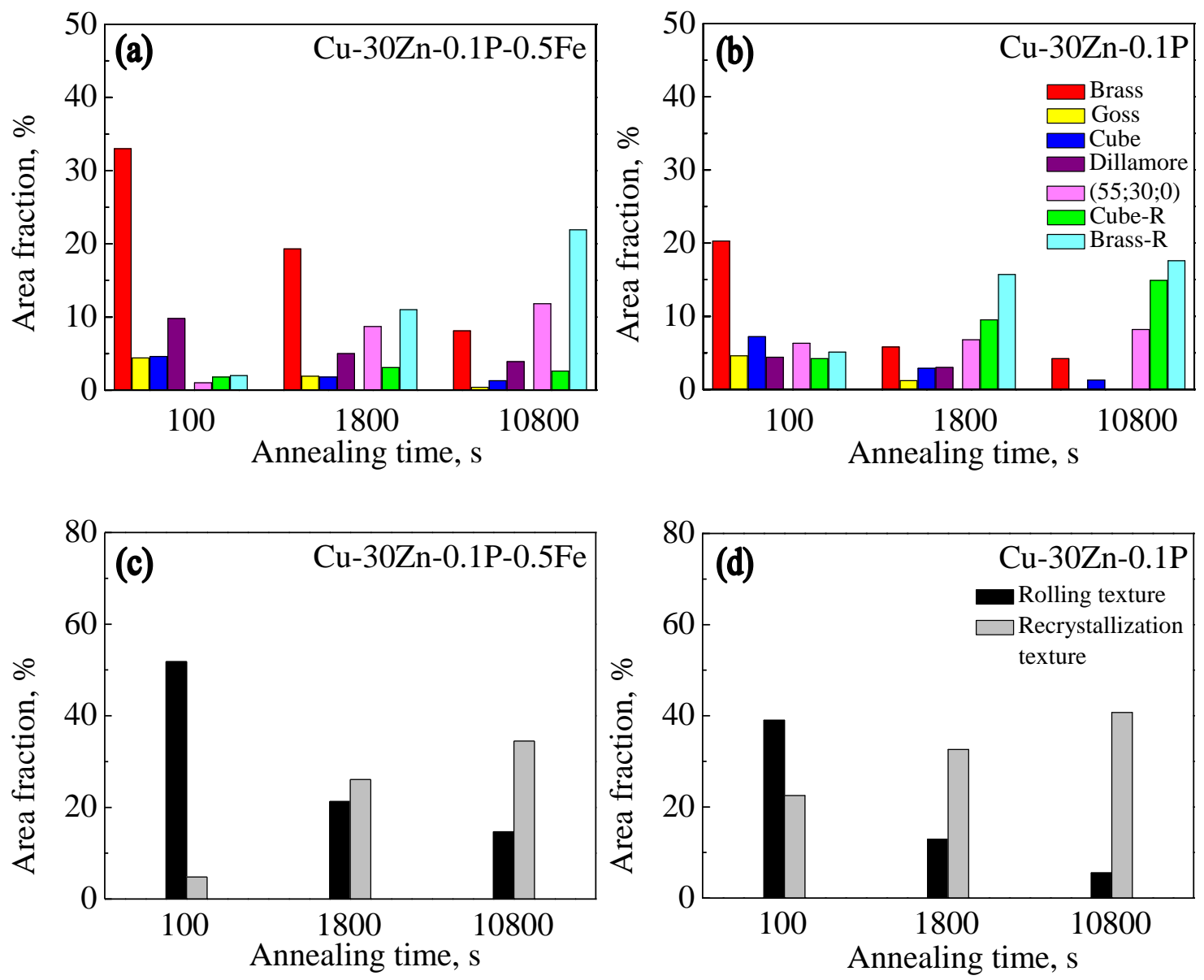